\title{
Clinical characteristics and outcomes of patients with $\mathrm{H} 1 \mathrm{~N} 1$ influenza pneumonia admitted at a tertiary care hospital in Karachi, Pakistan
}

\author{
Mujahid Hussain ${ }^{1 *}$ (D) Nosheen Nasir² ${ }^{2}$, Muhammad Irfan ${ }^{1}$ (D) and Zahra $\operatorname{Hasan}^{3}$ (D)
}

\begin{abstract}
Introduction: Influenza viruses specifically, A and B mainly contribute to seasonal outbreaks that occur globally. However, due to limited diagnostics for influenza there is little data regarding clinical outcomes of patients with H1N1 pneumonia in our region. Our objective was to determine the clinical characteristics and outcomes of patients hospitalized with H1N1 pneumonia at a tertiary care facility in Karachi, Pakistan.

Methods: A retrospective study of adult patients admitted with influenza pneumonia from November 2017 to February 2018 at a tertiary care hospital in Karachi, Pakistan. Patient characteristics were compared between influenza A H1N1 and other types of influenza using multivariable logistic regression analysis and subgroup analysis for factors associated with mortality in H1N1 Pneumonia was performed.

Results: Out of 497 adult patients with community acquired pneumonia (CAP), 172 fulfilled the criteria for Influenza like illness (ILI). 88 patients had PCR confirmed Influenza pneumonia of whom $n=57$ (65\%) had Influenza A H1N1. The mean age of patients 53.5 years (SD: 17.3) and 60\% were male. The overall mortality from Influenza in this study was 15.9\% $(n=14)$; out of these $11(78.5 \%)$ had Influenza A H1N1. Multivariable analysis showed that the increase in length of hospital admission was significantly associated with H1N1 Influenza A infection (OR: 1.47 Cl: 1.2-1.8). Factors associated with mortality showed that presence of ARDS, Septic shock and multi-organ failure was highly significantly associated with death ( $p$-value $<0.001)$ along with deranged liver function tests $(p$-value 0.01$)$ and presence of nosocomial infection ( $p$-value 0.027).

Conclusion: Influenza A H1N1 is associated with greater length of stay compared with infection due to other types of Influenza and mortality in H1N1 Pneumonia was found to be associated with presence of nosocomial infection among several other factors which may have implications given higher rates in a low-middle income country.
\end{abstract}

Keywords: Influenza, H1N1, Mortality

\section{Background}

Viral respiratory infections account for nearly $50 \%$ of acute respiratory illness. Influenza viruses A and B cause seasonal outbreaks with significant morbidity and mortality. The first influenza A (swine flu) virus of the

\footnotetext{
* Correspondence: hussain.mujahid@aku.edu

${ }^{1}$ Department of Medicine, Section of Pulmonary and Critical Care Medicine,

Aga Khan University, Karachi, Pakistan

Full list of author information is available at the end of the article
}

H1N1 subtype was isolated from in humans in 1974 [1]. In 2009, the World Health Organization (WHO) announced a swine-oriented influenza virus pandemic, H1N1 2009 pandemic [2]. During this outbreak in 2009/ 2010, around 18,500 deaths were reported associated with confirmed H1N1 influenza virus with a mortality rate of 0.12 deaths per 100,000 populations [3]. According to United States Centers for Disease Control and Prevention $(\mathrm{CDC})$, there were 12,470 fatal cases based

(c) The Author(s). 2020 Open Access This article is licensed under a Creative Commons Attribution 4.0 International License, which permits use, sharing, adaptation, distribution and reproduction in any medium or format, as long as you give

appropriate credit to the original author(s) and the source, provide a link to the Creative Commons licence, and indicate if changes were made. The images or other third party material in this article are included in the article's Creative Commons licence, unless indicated otherwise in a credit line to the material. If material is not included in the article's Creative Commons licence and your intended use is not permitted by statutory regulation or exceeds the permitted use, you will need to obtain permission directly from the copyright holder. To view a copy of this licence, visit http://creativecommons.org/licenses/by/4.0/. 
on data using mathematical models [4]. A majority of patients with Influenza A H1N1 subtype usually present with symptoms of upper and lower respiratory tract infections such as, sudden onset of fever, cough, sore throat, headache, myalgia, and generalized weakness. The symptoms may be self-limiting in most but it can progress to severe pneumonia, acute respiratory distress syndrome (ARDS) and mortality $[5,6]$. Studies have shown that up to $66 \%$ hospitalized patients had chest radiographic abnormalities compatible with pneumonia [3]. There are no unique clinical features that distinguish Influenza A subtype H1N1 infection from other forms of viral respiratory infections. Although a number of patients had predisposing immune-compromising conditions, healthy persons are also at risk for illness and death from H1N1 Influenza pneumonia [2]. In a study from Turkey; $30.6 \%$ patients presented with interstitial infiltrates on chest radiograph and $36 \%$ with consolidation [7]. Studies have shown increased severity of disease in pregnant women, transplant recipients and patients with malignancies $[8,9]$. There have been conflicting data from different parts of the world with some regions reporting better survival in ventilated patients [10] and some regions with poor outcomes in patients requiring intensive care [11].

Influenza A H1N1 has been reported globally but there is limited data available from Pakistan. In 2009, a single center case series reported 36 confirmed H1N1 cases with $16.7 \%$ mortality from in Pakistan [12]. Most of these cases were previously healthy individuals who developed an influenza-like illness that progressed to pneumonia within 5 to 7 days (5).

Despite yearly outbreaks each winter; data available from Pakistan on clinical characteristics and outcomes of $\mathrm{H} 1 \mathrm{~N} 1$ pneumonia patients is scarce $[12,13]$ and none is available from recent outbreaks. The aim of the study was to determine the clinical characteristics, course of disease and outcomes of these patients when hospitalized with H1N1 pneumonia in tertiary care hospital.

\section{Methods}

\section{Ethical approval}

This study received approval from the Ethical Review Committee of the hospital (5277-Med-ERC-18). The data was collected from hospital records and the requirement for informed consent was waived by the hospital ethical review committee as data was anonymized and no personal identifiers were collected.

\section{Study population and design}

We conducted a retrospective descriptive study of adult patients admitted with a diagnosis of Influenza pneumonia from November 2017 to February 2018 at a 700 bedded tertiary care hospital in Karachi, Pakistan. All patients admitted with the diagnosis of community acquired pneumonia during the study period were identified from the hospital information management system. Influenza-like illness (ILI) was defined as "An acute respiratory illness with a measured temperature of $\geq 38{ }^{\circ} \mathrm{C}$ and cough, with onset within the past 10 days" [14]. A confirmed case of influenza pneumonia was defined as an individual with an ILI with laboratory-confirmed influenza by Influenza virus PCR assay in respiratory specimen.

Demographic and clinical characteristics of confirmed influenza patients including, underlying medical and respiratory co-morbidities and laboratory and radiological investigations, treatment and complications during hospitalization were collected on a structured performa from hospital medical records.

\section{Diagnosis of influenza}

Nasopharyngeal swabs were processed for detection of Influenza virus by real-time reverse transcriptase polymerase chain reaction (RT-PCR) using the Influenza virus PCR assay (Altona Diagnostics, $\mathrm{GmbH}$ ).

Radiological diagnosis of pneumonia was made by evaluation of infiltrates observed on chest $\mathrm{X}$ ray and/or CT chest scans. A multidisciplinary team of doctors including infectious diseases consultants, pulmonologists and intensivits were involved in identification of cases and their management.

\section{Data analysis}

STATA ver 12.1was used for data analysis. Descriptive analysis was performed for demographic features with mean and standard deviation reported for quantitative variables such as age and lengths of hospital stay and frequencies (percentage) for qualitative variables such as gender, co-morbid conditions, mortality and complications etc. $X 2$ test of independence or Fischer Exact test was performed for comparison of factors between those with H1N1 Influenza compared to those with Influenza other than H1N1 subtype. Multivariable logistic regression analysis was performed on variables found to be significant on univariate analysis to identify factors associated with Influenza A H1N1 infection. All $p$ value $\leq 0.05$ was taken as significant. Subgroup analysis was also done using $x^{2}$ test of independence or Fischer Exact test for comparison between those who died compared to those who recovered from H1N1 Influenza.

\section{Results}

Total of 497 patients of age 18 years and above were admitted during this period with community acquired pneumonia (CAP) out of which 172 fulfilled the criteria for Influenza like illness (ILI). Out of 172 patients admitted with ILI, 88 (51\%) patients fulfilled the criteria of 
confirmed Influenza pneumonia. Majority of the patients had Influenza A H1N1 $(n=57) 65 \%$ while, $(n=6) 7 \%$ patients had non H1N1 Influenza A and $(n=25) 28 \%$ patients had Influenza B.

The mean age of patients with H1N1 Influenza was 53.5 years (SD: 17.3). Thirty-four patients (59.6\%) were female and six of them were pregnant. Hypertension was the commonest co-morbid condition as found in $44 \%$ of H1N1 cases. Sixty-three percent of the Influenza A H1N1 patients were non-smokers. Only three (5.2\%) patients had received quadrivalent inactivated influenza vaccination.

Risk factors associated with influenza were evaluated in patients with H1N1 influenza. None of the cases had a recent history of travel outside of the country or, had occupational exposure to livestock. Only one was a health care provider. The median duration of illness prior to presentation of Influenza was 5 days (IQR: 2) (Table 1). Amongst Influenza A H1N1 patients, 96\% patient had interstitial infiltrates on chest radiography and the most frequently associated lung condition was Chronic Obstructive Pulmonary disease (COPD) $(n=8)$. Of patients with Influenza A H1N1 subtype, microbiological cultures of respiratory secretions taken on admission were tested in 23 cases and were found to be positive in $6(26 \%)$ patients. Three patients had a polymicrobial growth of Staphylococcus aureus and Aspergillus species (two had A. flavus and one had A. fumigatus) and three patients had isolated growth of Aspergillus flavus. All patients with H1N1 influenza received Oseltamivir as well as antibiotics empirically.

The clinical outcomes of patients with Influenza A H1N1 infection are summarized in Table 2. The mean length of stay was 8 days (SD: 6). The overall mortality from Influenza virus infection during this period was $15.9 \%(14 / 88)$. Eleven $(78.5 \%)$ of 14 patients who died were positive for Influenza A H1N1 subtype. Further, the mortality in Influenza A subtype H1N1 pneumonia was $19 \%(11 / 57)$.

The laboratory parameters including mean white blood cell count, creatinine and blood glucose levels were similar for both patients with $\mathrm{H} 1 \mathrm{~N} 1$ and influenza other than H1N1 with the exception of transaminase levels (SGPT and SGOT) which had a higher trend in patients infected with Influenza A subtype H1N1 pneumonia (Supplementary Table 1).

Amongst patients with H1N1, nineteen (33.3\%) required ICU admission and mechanical ventilation whilst none of the other cases (with influenza A non-H1N1 or Influenza B), $p$-value: 0.001 . The mean duration of

Table 1 Baseline characteristics of patients with Influenza subtype H1N1 compared to other than H1N1 during the outbreak of 2017

\begin{tabular}{|c|c|c|c|}
\hline Characteristic & $\mathrm{H} 1 \mathrm{N1}(\mathrm{N}=57)$ & Other than H1N1 $(N=31)$ & $p$-value \\
\hline Mean Age \pm SD & $53.5 \pm 17.3$ & $61.3 \pm 12.6$ & 0.035 \\
\hline Mean CURB score \pm SD & $1.9 \pm 0.98$ & $1.5 \pm 0.99$ & 0.091 \\
\hline Median Duration Of IIIness (Range) & $5(2-10)$ & $4(2-7)$ & 0.636 \\
\hline Gender & & & 0.467 \\
\hline Male & 23 & 15 & \\
\hline Female & 34 & 16 & \\
\hline Pregnant & 6 & 0 & 0.001 \\
\hline Smoking status & & & 1.000 \\
\hline Current Smoker & 7 & 4 & \\
\hline Ex-Smoker & 11 & 6 & \\
\hline Non Smoker & 36 & 20 & \\
\hline Don't know & 3 & 1 & \\
\hline \multicolumn{4}{|l|}{ Co-morbids } \\
\hline Diabetes & 24 & 12 & 0.757 \\
\hline Hypertension & 25 & 18 & 0.203 \\
\hline COPD & 8 & 4 & \\
\hline Cardiac Problems & 13 & 3 & \\
\hline Obesity & 5 & 1 & \\
\hline CVA & 2 & 0 & \\
\hline Malignancy & 2 & 1 & \\
\hline Immunosuppression & 7 & 2 & \\
\hline
\end{tabular}


Table 2 Outcomes and Complications of patients with Influenza subtype H1N1 compared to other than H1N1 during the outbreak of 2017

\begin{tabular}{|c|c|c|c|}
\hline Variables & $\mathrm{H} 1 \mathrm{N1}(\mathrm{N}=57)$ & Other than H1N1 $(\mathrm{N}=31)$ & $p$-value \\
\hline \multicolumn{4}{|l|}{ Type of admission } \\
\hline ICU & 19 & 0 & 0.001 \\
\hline SCU & 28 & 17 & 0.968 \\
\hline Ward & 10 & 13 & 0.013 \\
\hline \multicolumn{4}{|l|}{ Management } \\
\hline Vasopressors & 13 & 1 & 0.016 \\
\hline Non-invasive ventilation & 20 & 9 & 0.564 \\
\hline Invasive Ventilation & 19 & 0 & $<0.001$ \\
\hline Mean Duration Of Intubation \pm SD & $3.06 \pm 4.97$ & 0 & \\
\hline Systemic Steroids & 23 & 11 & 0.654 \\
\hline Antibiotics & 56 & 29 & 0.282 \\
\hline Oseltamivir & 57 & 28 & 0.041 \\
\hline \multicolumn{4}{|l|}{ Complications } \\
\hline Respiratory Failure & 34 & 9 & 0.009 \\
\hline ARDS & 18 & 0 & $<0.001$ \\
\hline Septic Shock & 14 & 1 & 0.015 \\
\hline MODS & 13 & 3 & 0.157 \\
\hline Nosocomial Infection & 7 & 0 & 0.049 \\
\hline Acute Kidney Injury & 24 & 6 & 0.032 \\
\hline NSTEMI & 9 & 2 & 0.315 \\
\hline Outcome & & & 0.359 \\
\hline Recovered & 42 & 26 & \\
\hline Dead & 11 & 3 & \\
\hline Unknown & 4 & 2 & \\
\hline Median Length Of Stay (Range) & $6(1-25)$ & $3(0-12)$ & 0.001 \\
\hline
\end{tabular}

Abbreviations: ICU Intensive care unit; SCU Special care unit; ARDS Acute Respiratory Distress Syndrome; MODS Multi-organ dysfunction Syndrome; NSTEMI Non- ST elevation myocardial infarction

intubation was 3.06 days (SD: 4.97) among 19 patients, who required mechanical ventilation. This was significantly different when compared to patients who had influenza other than $\mathrm{H} 1 \mathrm{~N} 1$ as none of patients in that group required mechanical ventilation. The mortality among mechanically ventilated patient were $47.3 \%$ ( $n=$ 9/19). Twenty nine (33\%) patients required non-invasive ventilation (NIV). Twenty of 29 patients who required NIV had H1N1 pneumonia. Five patients who required NIV died and the association was not statistically significant ( $p=0.7) ; 4$ of these patients had H1N1 pneumonia.

The hospital course was complicated by nosocomial pneumonia in $8(14 \%)$ of those with H1N1 influenza compared to none in the other group ( $p$-value: 0.046 ) (Table 2). Patients were diagnosed to have superimposed infection based on culture and sensitivity results of sputum or bronchoscopy specimens obtained during course of hospital stay. Acinetobacter species was isolated in 5 patients and Pseudomonas aeruginosa was isolated in 3 patients. Aspergillus species were identified from sputum specimens of 8 patients, 6 at the time of admission and 2 during the course of hospital stay. Aspergillus flavus was the predominant species in 6 out of 8 specimens. 4 patients in whom Aspergillus species had been isolated had H1N1 pneumonia, one had Influenza A non- H1N1 and remaining had Influenza $B$ pneumonia. None of these patients required ICU admission and only one patient died.

Associated factors with H1N1 Influenza A compared to other Influenza types were assessed using univariate and multivariate analysis. In univariate analysis, presence of ARDS and invasive ventilation were found to be highly significant $(p=$ value $<0.001)$. Other significant risk factors included intensive care unit admission $(p$ value: 0.001$)$, septic shock ( $p$-value: 0.015$)$, respiratory failure ( $p$-value: 0.009$)$ and increase in length of stay $(p$ value: 0.001$)$. However in the multivariable analysis, only increase in length of stay was significantly associated 
with H1N1 Influenza infection (OR:1.47 CI: 1.2-1.8) and increase in age was found to be protective for H1N1 infection (OR:0.93 CI: 0.89-0.97) suggesting that H1N1 may be more predominantly affecting relatively younger age groups after adjusting for confounding.

Subgroup analysis for factors associated with mortality in H1N1 influenza was done using Fischer Exact test and it was found that presence of ARDS, Septic shock and multi-organ failure was highly significantly associated with death $(p$-value $<0.001)$ along with deranged liver function tests ( $p$-value 0.01$)$ and presence of nosocomial infection( $p$-value 0.027 ) (Table 3$)$.

\section{Discussion}

The World Health Organization (WHO) declared Influenza H1N1virus to have transitioned into post-pandemic period but with the potential to cause outbreaks in 2010. WHO Surveillance reports from December 2017 showed predominant circulation of influenza $\mathrm{A}(\mathrm{H} 1 \mathrm{~N} 1) \mathrm{pdm} 09$ virus with influenza $\mathrm{A}(\mathrm{H} 3 \mathrm{~N} 2)$ in Pakistan. Our study is the first from the country to describe the clinical characteristics and outcomes of patients affected with Influenza in that period. As per CDC, Influenza season between 2017 and 2018 was of high severity with multiple people visiting emergencies as well outpatient clinics with Influenza like illness and deaths due to pneumonia and influenza were reported to be approximately $10 \%$ nationally across the United States with predominant circulating strain being Influenza $\mathrm{A}(\mathrm{H} 3 \mathrm{~N} 2)$ [15]. As opposed to this, in Europe, the majority of cases were due to influenza virus type $B$ infection with excess mortality from all causes as per European Centre for Disease Prevention. However, from South Asia including, Afghanistan and India, the predominant strain was H1N1 [16]. In a single center study from India, the mortality was 29\% but it did not include cases from the 2017 outbreak. In our study, overall mortality from Influenza was $15.9 \%$ and mortality from H1N1 subtype was $19 \%$. Study from Pakistan sentinel sites reported $11 \%$ mortality from H1N1 in 2009 [13] and $16 \%$ in another single center study [12]. Mean age in our cohort was 55 years as opposed to 36 years during the 2009 Influenza outbreak in Pakistan [13].

Table 3 Subgroup analysis for mortality in H1N1 pneumonia

\begin{tabular}{llll}
\hline Variables & Died $(n=11)$ & Recovered $(n=42)$ & $p$-value \\
\hline Invasive ventilation & 9 & 9 & $<0.001$ \\
Respiratory failure & 10 & 20 & 0.001 \\
ARDS & 10 & 7 & $<0.001$ \\
Septic Shock & 10 & 4 & $<0.001$ \\
MODS & 9 & 2 & $<0.001$ \\
Nosocomial Infection & 4 & 3 & 0.027 \\
Transaminitis & 7 & 6 & 0.010 \\
\hline
\end{tabular}

Abbreviations: ARDS Acute Respiratory Distress Syndrome; MODS Multi-organ dysfunction Syndrome
However gender distribution also reflected similar predilection for females [12]. Among the risk factors, we did not find significant association with smoking or obesity as reported from other studies $[17,18]$ and majority of our patients were non-smokers as opposed to another study from Pakistan [13]. Eighteen percent required ICU admission as compared to $27 \%$ in another study done during the 2009 pandemic [12].

Secondary bacterial pneumonia is a well-recognized complication of influenza and most commonly implicated organisms include Staphylococcus aureus Streptococcus pneumonia and Klebsiella sp. [19]. In our study we found Aspergillus species in 6 out of 23 sputum specimens sent at admission with 3 having concomitant Staphylococcus aureus. S. aureus has been reported to cause superimposed infection in patients with H1N1 influenza [20, 21]. However, Aspergillus species have recently been reported to complicate severe influenza infections [22]. Influenza associated Aspergillosis (IAA) has been reported to occur in immunocompetent patients with Influenza and a large multicenter study from Netherlands reported 16\% IAA in their cohort. They also concluded that approximately all cases that have been reported so far are associated with influenza A H1N1 infection [23]. However, the limitation of our study is that we could not differentiate colonization with Aspergillus from Influenza associated Aspergillosis. Moreover our study has limited generalizability as it's a single center study. Findings from this study have implications for management in developing countries where the burden of multi-drug resistant healthcare associated infections and invasive fungal infections is high $[24,25]$ and may adversely affect outcomes in Influenza A H1N1 pneumonia since mortality is greater in patient who developed nosocomial infections.

\section{Conclusion}

Influenza A H1N1 is associated with greater length of stay compared with infection due to other types of Influenza and mortality in H1N1 Pneumonia was found to be associated with presence of nosocomial infection among several other factors which may have implications given higher rates in a low-middle income country.

\section{Supplementary information}

Supplementary information accompanies this paper at https://doi.org/10. 1186/s41479-020-00070-7.

Additional file 1: Supplementary Table 1. Laboratory Data for H1N1 pneumonia patients compared to Influenza other than H1N1.

Abbreviations: WBC: White blood cell count; CRP: C-reactive protein; SGPT: Serum glutamic pyruvic transaminase.

Abbreviations

WHO: World Health Organization; CDC: Centers for Disease Control and Prevention; ARDS: Acute respiratory distress syndrome; ERC: Ethical Review Committee; ILI: Influenza-like illness; RT-PCR: Real-time reverse transcriptase 
polymerase chain reaction; CAP: Community acquired pneumonia; COPD: Chronic Obstructive Pulmonary disease; SGPT: Serum glutamic pyruvic transaminase; SGOT: Serum glutamic-oxaloacetic transaminase; ICU: Intensive care unit; NIV: Non-invasive ventilation; IAA: Influenza associated aspergillosis

\section{Acknowledgements}

Not applicable.

\section{Authors' contributions}

$\mathrm{MH}$ : Conceived idea, supervised data collection, major contributor of manuscript. NN: Data collection, data analysis and contribution in writing manuscript. MI: Conceived idea, reviewed manuscript, provided expert opinion and supervised the study. Z $\mathrm{H}$ : Conceived idea, reviewed manuscript, provided expert opinion and supervised the study. All authors discussed the results and contributed to the final manuscript. The author(s) read and approved the final manuscript.

\section{Funding}

None.

\section{Availability of data and materials}

All data generated or analysed during this study are included in this published article.

\section{Ethics approval and consent to participate}

Ethical exemption was obtained from the Aga Khan University's Ethics Review Committee with Reference number: (5277-Med-ERC-18).

\section{Consent for publication}

Not applicable.

\section{Competing interests}

No conflict of interest.

\section{Author details}

${ }^{1}$ Department of Medicine, Section of Pulmonary and Critical Care Medicine, Aga Khan University, Karachi, Pakistan. ${ }^{2}$ Department of Medicine, Section of Infectious Diseases, Aga Khan University, Karachi, Pakistan. ${ }^{3}$ Department of Pathology and Laboratory Medicine, Section of Molecular Pathology, Aga Khan University, Karachi, Pakistan.

Received: 6 February 2020 Accepted: 8 June 2020

Published online: 05 July 2020

\section{References}

1. Smith TF, Burgert EO Jr, Dowdle WR, Noble GR, Campbell RJ, Van Scoy RE. Isolation of swine influenza virus from autopsy lung tissue of man. N Engl J Med. 1976:294(13):708-10.

2. Perez-Padilla R, De La Rosa-zamboni D, Ponce de Leon S, Hernandez M, Quiñones-Falconi F, Bautista $E$, et al. Pneumonia and respiratory failure from swine-origin influenza a (H1N1) in Mexico. N Engl J Med. 2009;361(7):680-9.

3. Jain S, Kamimoto L, Bramley AM, Schmitz AM, Benoit SR, Louie J, et al. Hospitalized patients with 2009 H1N1 influenza in the United States, AprilJune 2009. N Engl J Med. 2009;361(20):1935-44.

4. Morales KF, Paget J, Spreeuwenberg P. Possible explanations for why some countries were harder hit by the pandemic influenza virus in 2009-a global mortality impact modeling study. BMC Infect Dis. 2017;17(1):642

5. Okur M, Erbey F, Yazicioglu O, Celik A, Tukenmez B, Sunnetcioglu M, et al. H1N1 influenza a virus related pneumonia and respiratory failure. Ind J Virol. 2013;24(1):85-9

6. Hernandez-Cardenas CM, Serna-Secundino H, Garcia-Olazaran JG, AguilarPerez CL, Rocha-Machado J, Campos-Calderon LF, et al. Acute respiratory distress syndrome secondary to influenza a(H1N1)pdm09: clinical characteristics and mortality predictors. Rev Investig Clin. 2016;68(5):235-44.

7. Hacimustafaoglu M. Pandemic H1N1 influenza infections in 2009. Turk Pediatri Arsivi-Turkish Arch Pediatr. 2010:45:31-6.

8. Borse RT, Kadam DB, Sangle SA, Basavraj A, Prasad HB, Umarji PB, et al. Comparison of demographic, clinical, radiological characteristics and comorbidities in mechanically ventilated and nonventilated, adult patients admitted in ICU with confirmed diagnosis of influenza a (H1N1). J Assoc Physicians India. 2013;61(12):887-93.
9. Helantera I, Janes R, Anttila VJ. Clinical efficacy of seasonal influenza vaccination: characteristics of two outbreaks of influenza a(H1N1) in immunocompromised patients. J Hosp Infect. 2018;99(2):169-74.

10. Martinez-Briseno D, Torre-Bouscoulet L, Herrera-Zamora Jde J, Diaz-Rico J, Sandoval-Macias G, Perez-Padilla R, et al. Clinical characteristics and mortality of influenza a H1N1 and influenza-like illness in Mexico City in the 2013-2014 winter season. Rev Investig Clin. 2016;68(3):147-53.

11. Zhou F, Li H, Gu L, Liu M, Xue CX, Cao B, et al. Risk factors for nosocomial infection among hospitalised severe influenza a(H1N1)pdm09 patients. Respir Med. 2018;134:86-91.

12. Naseem A, Satti S, Khan MA, Saeed W. A clinical account of hospitalized 2009 pandemic influenza a (H1N1) cases. J Coll Physicians Surg Pak. 2011; 21(2):97-102.

13. Nisar N, Aamir UB, Badar N, Mehmood MR, Alam MM, Kazi BM, et al. Prediction of clinical factors associated with pandemic influenza a (H1N1) 2009 in Pakistan. PLoS One. 2014;9(2):e89178.

14. Fitzner J, Qasmieh S, Mounts AW, Alexander B, Besselaar T, Briand S, et al. Revision of clinical case definitions: influenza-like illness and severe acute respiratory infection. Bull World Health Organ. 2018;96(2):122-8.

15. Dugan VG, Blanton L, Elal AIA, Alabi N, Barnes J, Brammer L, et al. Update: influenza activity - United States, October 1-November 25, 2017. MMWR Morb Mortal Wkly Rep. 2017:66(48):1318-26.

16. Control ECfDPa. Seasonal influenza. ECDC: Stockholm; 2018

17. Barker WH, Mullooly JP. Pneumonia and influenza deaths during epidemics: implications for prevention. Arch Intern Med. 1982;142(1):85-9.

18. Paules C, Subbarao K. Influenza. Lancet. 2017:390(10095):697-708.

19. Metersky ML, Masterton RG, Lode H, File TM Jr, Babinchak T. Epidemiology, microbiology, and treatment considerations for bacterial pneumonia complicating influenza. Int J Infect Dis. 2012;16(5):e321-31.

20. Chung DR, Huh K. Novel pandemic influenza a (H1N1) and communityassociated methicillin-resistant Staphylococcus aureus pneumonia. Expert Rev Anti-Infect Ther. 2015;13(2):197-207

21. Park SS, Kim SH, Kim M, Kim JW, Ko YM, Kim SK, et al. A case of severe pseudomembranous Tracheobronchitis complicated by co-infection of influenza a (H1N1) and Staphylococcus aureus in an Immunocompetent patient. Tuberc Respir Dis. 2015;78(4):366-70.

22. Crum-Cianflone NF. Invasive Aspergillosis Associated With Severe Influenza Infections. Open Forum Infect Dis. 2016;3(3):ofw171.

23. van de Veerdonk FL, Kolwijck E, Lestrade PP, Hodiamont CJ, Rijnders BJ, van Paassen J, et al. Influenza-Associated Aspergillosis in Critically III Patients. Am J Respir Crit Care Med. 2017;196(4):524-7.

24. Alp E, Damani N. Healthcare-associated infections in intensive care units: epidemiology and infection control in low-to-middle income countries. J Infect Dev Countries. 2015;9(10):1040-5.

25. Warnock DW. Trends in the epidemiology of invasive fungal infections. Nihon Ishinkin Gakkai zasshi. 2007:48(1):1-12

\section{Publisher's Note}

Springer Nature remains neutral with regard to jurisdictional claims in published maps and institutional affiliations.

Ready to submit your research? Choose BMC and benefit from:

- fast, convenient online submission

- thorough peer review by experienced researchers in your field

- rapid publication on acceptance

- support for research data, including large and complex data types

- gold Open Access which fosters wider collaboration and increased citations

- maximum visibility for your research: over $100 \mathrm{M}$ website views per year

At BMC, research is always in progress.

Learn more biomedcentral.com/submission 